\title{
RESOLUTIONS OF THE PLENUM OF THE SUPREME COURT OF THE RUSSIAN FEDERATION: THEORETICAL AND LAW ENFORCEMENT ASPECT (WITHIN THE ANALYSIS OF RESOLUTION OF THE PLENUM OF THE SUPREME COURT OF THE RUSSIAN FEDERATION OF DECEMBER 4, 2014 No. 16)
}

\author{
Olga A. Yakovleva \\ Volgograd State University, Volgograd, Russian Federation \\ Svetlana S. Yablochkina \\ Kuban State University, Krasnodar, Russian Federation
}

Introduction: the question of the role of the Resolutions of the Plenum of the Supreme Court of the Russian Federation in the classification of crime is relevant in the realities of modern life. The dispositions of the articles of criminal law contain the essential elements of crimes, however, in view of the legislative technique, some of them are not disclosed by the legislator directly in the legal act. The Resolutions of the Plenum of the Supreme Court of the Russian Federation are interpretative acts that, based on the generalization and analysis of the judicial practice, ensure the uniform application of the Criminal Code within the territory of the Russian Federation. The purpose of the work is to determine the necessity degree of the acts of interpretation of the Supreme Court of the Russian Federation for the law enforcement practice on the basis of the illustrations of the discussion provisions of Resolution of the Plenum of the Supreme Court of the Russian Federation of December 4, 2014 no. 16. Methods: the methodological framework for the research is a whole set of methods; the priority is the method of system analysis and synthesis, as well as the formal legal method. Results: the paper analyzes the legal nature of the Resolutions of the Plenum of the Supreme Court of the Russian Federation. The act of interpretation of the highest judicial instance of the country devoted to crimes against sexual freedom and inviolability illustrates the influence of the judges of the Supreme Court of the Russian Federation on the law enforcement practice. The authors identified the problematic aspects contained in Resolution of the Plenum of the Supreme Court of the Russian Federation of December 4, 2014 no. 16 requiring the appropriate resolution. Conclusions: the question of the legal nature of the Resolutions of the Plenum of the Supreme Court of the Russian Federation will remain relevant among the legal theorists for a long period. In the meantime, the law enforcement practice will be built in accordance with the explanations of the higher courts until the legislative resolution of this issue.

Key words: precedent, act of interpretation, classification of crimes, crimes against sexual freedom and inviolability, criminal proceedings.

Citation. Yakovleva O.A., Yablochkina S.S. Resolutions of the Plenum of the Supreme Court of the Russian Federation: Theoretical and Law Enforcement Aspect (Within the Analysis of Resolution of the Plenum of the Supreme Court of the Russian Federation of December 4, 2014 no. 16). Legal Concept, 2020, vol. 19, no. 1, pp. 120-125. (in Russian). DOI: https://doi.org/10.15688/lc.jvolsu.2020.1.17 
ПОСТАНОВЛЕНИЯ ПЛЕНУМА ВЕРХОВНОГО СУДА РОССИЙСКОЙ ФЕДЕРАЦИИ: ТЕОРЕТИЧЕСКИЙ И ПРАВОПРИМЕНИТЕЛЬНЫЙ АСПЕКТЫ (В РАМКАХ АНАЛИЗА ПОСТАНОВЛЕНИЯ ПЛЕНУМА ВЕРХОВНОГО СУДА РОССИЙСКОЙ ФЕДЕРАЦИИ ОТ 4 ДЕКАБРЯ 2014 г. № 16)

\title{
Ольга Алексеевна Яковлева
}

Волгоградский государственный университет, г. Волгоград, Российская Федерация

\section{Светлана Сергеевна Яблочкина}

Кубанский государственный университет, г. Краснодар, Российская Федерация

\begin{abstract}
Введение: вопрос о роли Постановлений Пленума Верховного Суда Российской Федерации в квалификации преступлений является актуальным в современной реальности. Диспозиции статей Уголовного закона содержат признаки составов преступлений, однако ввидузаконодательной техники часть из них не раскрывается законодателем непосредственно в нормативно-правовом акте. Постановления Пленума Верховного Суда Российской Федерации выступают толковательными актами, которые на основе обобщения и анализа судебной практики обеспечивают единообразное применение норм Уголовного кодекса на территории Российской Федерации. Целью работы выступает определение степени обязательности актов толкования Верховного Суда Российской Федерации для правоприменительной практики на основе иллюстраций дискуссионных положений Постановления Пленума Верховного Суда Российской Федерации от 4 декабря 2014 г. № 16. Методологическую основу исследования составляет целый комплекс методов, в качестве приоритетных выделяем метод системного анализа и синтеза, а также формально-юридический метод. Результаты: в данной работе проведен анализ юридической сущности Постановлений Пленума Верховного Суда Российской Федерации. Акт толкования высшей судебной инстанции страны, посвященный преступлениям против половой свободы и неприкосновенности, иллюстрирует влияние судей Верховного Суда Российской Федерации на правоприменительную практику. Авторами выявлены проблемные аспекты, содержащиеся в Постановлении Пленума Верховного Суда Российской Федерации от 4 декабря 2014 г. № 16, требующие соответствующего разрешения. Выводы: вопрос о юридической природе Постановлений Пленума Верховного Суда РФ будет оставаться актуальным среди теоретиков правовой мысли на протяжении долгого периода. В то же время правоприменительная практика будет строиться в соответствии с разъяснениями высших судебных инстанций до момента законодательного разрешения этого вопроса.

Ключевые слова: прецедент, акт толкования, квалификация преступлений, преступления против половой свободы и неприкосновенности, уголовное судопроизводство.
\end{abstract}

Цитирование. Яковлева О. А., Яблочкина С. С. Постановления Пленума Верховного Суда Российской Федерации: теоретический и правоприменительный аспекты (в рамках анализа Постановления Пленума Верховного Суда Российской Федерации от 4 декабря 2014 г. № 16) // Legal Concept = Правовая парадигма. 2020. - T. 19, № 1. - C. 120-125. - DOI: https://doi.org/10.15688/lc.jvolsu.2020.1.17

\section{Введение}

Прецедент как источник права характерен для англо-саксонской правовой семьи, под ним понимается решение конкретного судебного органа по определенному делу, которое является обязательным для последующих аналогичных случаев [6, с. 867]. Особенность данного правового явления заключается в том, что оно выступает не просто решением по делу, а составляет часть системы общего права. Английские юристы выработали правило, в соответствии с которым судьи употребляют часть прецедента в правовой аргументации судебного решения. Значение этого правила состоит в том, что прецедент закладывает правовые принципы, применяемые к конкретным обстоятельствам дела при разрешении правовых вопросов. 
В рамках уголовного судопроизводства правило прецедента посредством правовой аргументации подлежит применению при рассмотрении и разрешении конкретного уголовного дела. Как уже отмечалось, прецедент выступает в качестве правовой нормы, применение которой обязательно. Для признания судебного решения прецедентом, необходимо, чтобы были соблюдены определенные условия: обязательность судебного решения, вынесение по конкретному уголовному делу, посредством решения формулируется норма права [8, с. 170].

Иначе обстоят дела в Российской Федерации, которая в силу исторических особенностей развития относится к романо-германской правовой семье. В России основным источником права признается закон, а судебная практика не является частью правовой системы страны.

\section{Дискуссия о правовой сущности Постановлений Пленума}

\section{Верховного Суда Российской Федерации}

Конституция РФ в главе, посвященной судебной власти и прокуратуре, в ст. 126 закрепляет статус Верховного Суда РФ. Основной закон страны признает его высшим судебным органом различной юрисдикционной направленности, закрепляет возможность отражения в федеральном законе процессуальных форм судебного контроля над нижестоящими инстанциями, наделяет полномочиями разъяснения по вопросам судебной практики. Несмотря на законодательное закрепление, проблема обязательности Постановлений Пленума Верховного Суда РФ, в том числе дающих разъяснение по уголовно-правовым вопросам, тревожат умы ученых доктрины уголовного права по сей день. Мнения авторов разделились: одни придерживаются точки зрения законодателя [2, с. 262]; другие настаивают на рекомендательном характере актов высшего судебного органа страны [4, с. 35], третьи выступают за тезис о толковании уголовного закона в Постановлениях Пленума Верховного Суда РФ [1, с. 42; 7 , с. 46], часть авторов выступает за нормативно-подзаконный характер указанных актов $[3$, с. 5].
Существует и другая точка зрения. Например, В.Н. Синюков настаивает на придании им статуса судебного прецедента [7]. Аргументация данной позиции выглядит следующим образом, во-первых, явный недостаток нормативного материала, во-вторых, противоречивость законодательных положений. Несомненно, описанные выше проблемы имеют место быть, и Уголовный закон не является исключением. Однако придание Постановлениям Пленума Верховного Суда РФ статуса судебного прецедента означало бы, что судебный орган наделяется законодательным полномочием, что противоречит основам, заложенным в Конституции России. Сущность этих актов состоит в иллюстрации негативных тенденций законодательства путем обобщения судебных решений, а также разъяснении некоторых положений закона при условии сохранения его смысла.

\section{Роль Постановлений Пленума Верховного Суда РФ при квалификации преступлений}

Так, для наиболее точной и полной квалификации преступления недостаточно ограничиваться знанием диспозиции уголовного закона, существует необходимость толкования содержащихся положений, в том числе и при их нераскрытости в Уголовном кодексе РФ. Российский законодатель должен излагать материал лаконично и распространять формулировки на большее количество деяний. Ввиду указанного обстоятельства Постановления Пленума Верховного Суда РФ служат актами толкования, внося ясность и единообразие в правоприменительную практику.

Например, п. «а» ч. 2 ст. 131 УК РФ содержит такой признак состава преступления, как «изнасилование, совершенное группой лиц, группой лиц по предварительному сговору или организованной группой лиц», не раскрывая данного положения. Следовательно, правоприменитель задается вопросом понимания обозначенного признака в контекстеуказанной статьи. Пункт 10 Постановления Пленума Верховного Суда Российской Федерации от 4 декабря 2014 г. № 16 отражает важные моменты, касающиеся квалификации групповых насильственных преступлений. Под признак групповых преступлений, 
посягающих на половую свободу и неприкосновенность, попадают не только преступления, совершенные несколькими виновными в адрес одной потерпевшей, но и:

- совершение деяния несколькими лицами, при котором осуществлялось запугивание нескольких потерпевших, впоследствии ставших жертвами изнасилования или действий сексуального характера указанными субъектами, например, двое мужчин, угрожая расправой двум потерпевшим, вступили в половую связь с каждой из них;

- совершение деяния несколькими лицами, при котором осуществлялось запугивание нескольких потерпевших, однако изнасилованию или действиям сексуального характера подверглась одна из них;

- соисполнительством признается деяние, в котором один из виновных непосредственно осуществляет изнасилование или действия сексуального характера, а другое лицо оказывает содействие в совершении преступления путем физического или психического воздействия на потерпевшую, несмотря на то что оно не вступает в половую связь с потерпевшей. Ввиду этого необходимо признать соисполнительством и тот случай, когда один из обвиняемых приводит лицо в беспомощное состояние, а другой совершает половой акт;

- ситуации, когда лицо непосредственно не совершает изнасилование или действия сексуального характера, а также не оказывает психологического или физического воздействия, но другими способами содействует совершению преступления (например, советами, сообщением определенной информации, устранением препятствий), квалифицируются по ст. 131, 132 УК РФ со ссылкой на ч. 5 ст. 33 УК РФ.

Для того чтобы описанные выше случаи можно было квалифицировать как групповое преступление, они должны обладать признаком согласованности действий лиц. Она может быть выражена в сознательном объединении усилий для совершения деяний, направленных против половой свободы и неприкосновенности.

Как мы видим, признак «изнасилование, совершенное группой лиц, группой лиц по предварительному сговору или организованной группой» подробно раскрыт высшей судебной инстанцией Российской Федерации, что создает благоприятные условия для вынесения законных приговоров нижестоящими судами. Однако Пленум Верховного Суда РФ не дает разьяснений, как поступать правоприменителю в случае, когда одно лицо попадает под признаки субъекта данного состава преступления, а другое не осознает характер совершаемых действий ввиду невменяемого состояния или малолетнего возраста. Полагаем, существует необходимость внесения соответствующих разъяснений в Постановление № 16 от 2014 года.

\section{Цели Постановлений Пленума Верховного Суда Российской Федерации}

Хотелось бы так же отметить, что акты толкования Пленума высшего судебного органа судов общей юрисдикции преследуют цель правильного понимания законов судьями, но это не единственная цель разъяснений, так как указанная деятельность в том числе направлена на разрешение дел судами в точном соответствии с действующим законодательством, а также принципами и нормами международного правотворчества. Однако существуют положения в разъяснениях, которые относятся к дискуссионным.

В качестве примера можно привести положения, касающиеся умышленного и неосторожного заражения лица ВИЧ-инфекцией при совершении изнасилования или насильственных действий сексуального характера. Противоречие положений Постановления Пленума и норм Уголовного закона состоит в следующем. Законодатель предусматривает в качестве квалифицирующего признака составов преступлений, предусмотренных ст. 131, 132 УК РФ, неосторожное заражение лица ВИЧ-инфекцией, следовательно, при умышленном заражении потерпевших ВИЧинфекцией квалификация должна выглядеть следующим образом - совокупность ст. 131 и/или 132 УК РФ и ст. 122 УК РФ. Несмотря на это, в разъяснениях Пленума Верховного Суда РФ данное деяние поглощается п. «б» ч. 3 ст. 131 УК РФ и/или п. «б» ч. 3 ст. 132 УК РФ, тем самым нарушается верховенство уголовного закона.

Другой пример коснется составов преступлений, признаки которых раскрываются в ст. 134, 135 УК РФ, по ним Верховный Суд 
также дает разъяснения. В п. 16 обозначенного нами Постановления говорится, что половое сношение, лесбиянство и мужеложство, а также развратные действия, совершенные в отношении лица, достигшего 12-летнего возраста, но не достигшего 16-летнего возраста, без использования насилия, угроз или беспомощного состояния квалифицируются по ст. 134, 135 УК РФ, те же действия с лицом, не достигшим 12-летнего возраста, квалифицируются по ст. 131, 132 УК РФ в зависимости от обстоятельств совершенного преступления.

А.Н. Попов указал, что Пленум Верховного Суда РФ не уделяет внимание тому факту, что диспозиция ст. 134 УК РФ предусматривает ответственность за половое сношение, мужеложство и лесбиянство без использования насилия, угроз, беспомощного состояния со специальным субъектом, имеющим возрастной ценз (12 лет включительно, но не старше 16 лет). Указанная статья уголовного закона не устанавливает ответственности за иные действия сексуального характера, которые не содержатся в диспозиции ст. 134 УК РФ, а Постановление Пленума не дает четкого ответа на этот вопрос [5, с. 27].

Дискуссионность состоит в соотношении иных действий сексуального характера и развратных действий. Законодатель разграничивает данные понятия, что следует из названия ст. 134 и 135 УК РФ. Однако в п. 17 Постановления Пленума Верховного Суда РФ № 16 от 2014 г. дается описание развратных действий, куда включаются все деяния, кроме полового сношения, лесбиянства и мужеложства, преследующие цели удовлетворения сексуального влечения виновного, возбуждение и вызывание сексуального интереса у потерпевшего. Следовательно, развратные действия включают в себя иные действия сексуального характера. Поспорим с данным положением, ведь половое сношение в иной форме представляет большую общественную опасность, чем развратные действия. Поэтому необходимо внести соответствующие коррективы в толковательный акт.

\section{Выводы}

Из представленных примеров мы наблюдаем, что в Постановлениях Пленума могут содержаться дискуссионные положения. Несмотря на это, следует согласиться с авторами, относящими акты толкования высшей национальной судебной инстанции к числу обязательных для судей нижестоящих судов, судьи выносят приговоры в соответствии с ними, хотя в законодательстве отсутствует такая обязанность.

Таким образом, вопрос о юридической природе Постановлений Пленума Верховного Суда Российской Федерации будет оставаться актуальным среди теоретиков правовой мысли на протяжении долгого периода. В то же время правоприменительная практика будет строиться в соответствии с разъяснениями высших судебных инстанций до момента законодательного разрешения этого вопроса.

\section{СПИСОК ЛИТЕРАТУРЫ}

1. Гарбатович, Д. А. Разъяснения Пленума Верховного Суда РФ о назначении уголовного наказания / Д. А. Гарбатович // Вестник ЮУрГУ. Серия «Право». - 2015. - Т. 15, № 3. - С. 42-46.

2. Голунский, С. А. Теория государства и права / С. А. Голунский, М. С. Строгович. - М., 1940. $-304 \mathrm{c}$.

3. Даниелян, А. С. Постановления Пленума Верховного Суда РФ как форма выражения судебного правотворчества / А. С. Даниелян, И. Н. Гелиева // Юридическая наука. - 2018. - № 4. - С. 3-6.

4. Нерсесянц, В. С. Суд не законодательствует и не управляет, а применяет право (о правоприменительной природе судебных актов) / В. С. Нерсесянц // Судебная практика как источник права. M., 1997.-C. 34-41.

5. Попов, А. Н. Комментарий к Постановлению Пленума Верховного Суда Российской Федерации «О судебной практике по делам о преступлениях против половой неприкосновенности и половой свободы личности» / А. Н. Попов. - СПб. : Изд-во С.-Петерб. юрид. ин-та (фил.) Акад. Генеральной прокуратуры Рос. Федер., 2016. - 40 с.

6. Прецедент / В. Т. Кабышев, Н. М. Конин, Н. А. Лопашенко, Н. И. Матузов // Юридическая энциклопедия / гл. ред. Б. Н. Топорнин. - М. : Юристь, 2001.- 1267 с.

7. Синюков, В. Н. Российская правовая система: введение в общую теорию / В. Н. Синюков. Саратов : Полиграфист, 1994. - 495 с.

8. Яковлева, О. А. Роль Постановлений Пленума Верховного Суда Российской Федерации в правоприменительной практике (экологический ас- 
пект) / О. А. Яковлева // Вестник Волгоградского государственного университета. Серия 5, Юриспруденция. - 2016. - № 3 (32). - C. 170-174. - DOI: https://doi.org/10.15688/jvolsu5.2016.3.25.

\section{REFERENCES}

1. Garbatovich D.A. Razyasneniya Plenuma Verkhovnogo Suda RF o naznachenii ugolovnogo nakazaniya [Clarifications of the Plenum of the Supreme Court of the Russian Federation on the Imposition of Criminal Punishment]. Vestnik YuUrGU. Seriya «Pravo», 2015, vol. 15, no. 3, pp. 42-46.

2. Golunskiy S.A., Strogovich M.S. Teoriya gosudarstva i prava [Theory of State and Law]. Moscow, 1960. 304 p.

3. Daniyelyan A.S., Geliyeva I.N. Postanovleniya Plenuma Verkhovnogo Suda RF kak forma vyrazheniya sudebnogo pravotvorchestva [Decisions of the Plenum of the Supreme Court of the Russian Federation as a Form of Expression of Judicial Law-Making]. Yuridicheskaya nauka [Legal Science], 2018, no. 4, pp. 3-6.

4. Nersesyants V.S. Sud ne zakonodatelstvuyet i ne upravlyayet, a primenyayet pravo (o pravoprimenitelnoy prirode sudebnykh aktov) [The Court Does Not Legislate or Administer, but Applies the Law (on the Enforcement Nature of Judicial Acts)].
Sudebnaya praktika kak istochnik prava [Judicial Practice as a Source of Law]. Moscow, 1997, pp. 34-41.

5. Popov A.N. Kommentariy k Postanovleniyu Plenuma Verkhovnogo Suda Rossiyskoy Federatsii «O sudebnoy praktike po delam o prestupleniyakh protiv polovoy neprikosnovennosti $i$ polovoy svobody lichnosti» [Commentary on the Resolution of the Plenum of the Supreme Court of the Russian Federation "On Judicial Practice in Cases of Crimes Against Sexual Integrity and Sexual Freedom of the Individual"]. Saint Petersburg, 2016. 40 p.

6. Kabyshev V.T., Konin N.M., Lopashenko N.A., Matuzov N.I. Pretsedent [Precedent]. Topornin B.N., ed. Yuridicheskaya entsiklopediya [Legal Encyclopedia]. Moscow, Yurist Publ., 2001. 1267 p.

7. Sinyukov V.N. Rossiyskaya pravovaya sistema: vvedeniye $v$ obshchuyu teoriyu [Russian Legal System: Introduction to the General Theory]. Saratov, Poligrafist, 1994. 495 p.

8. Yakovleva O.A. Rol Postanovleniy Plenuma Verkhovnogo Suda Rossiyskoy Federatsii V pravoprimenitelnoy praktike (ekologicheskiy aspekt) [The Role of the Judgments of the Plenum of the Supreme Court of the Russian Federation in Law Enforcement Practice (Environmental Aspect)]. Vestnik Volgogradskogo gosudarstvennogo universiteta. Seriya 5, Yurisprudentsiya [Bulletin of Volgograd State University. Series5, Jurisprudence], 2016, no. 3 (32), pp. 170-174. DOI: https://doi.org/10.15688/jvolsu5.2016.3.25.

\section{Information About the Authors}

Olga A. Yakovleva, Candidate of Sciences (Jurisprudence), Associate Professor, Department of Criminal Law, Volgograd State University, Prosp. Universitetsky, 100, 400062 Volgograd, Russian Federation, olgayakovlev@mail.ru, https://orcid.ord/0000-0002-6833-5005

Svetlana S. Yablochkina, Master Student, Faculty of Law Named After A.A. Khmyrov, Kuban State University, Stavropolskaya St., 149,350040 Krasnodar, Russian Federation, swetlana.jablo4kina@yandex.ru, https://orcid.org/0000-0001-8124-213X

\section{Информация об авторах}

Ольга Алексеевна Яковлева, кандидат юридических наук, доцент кафедры уголовного права, Волгоградский государственный университет, просп. Университетский, 100, 400062 г. Волгоград, Российская Федерация, olgayakovlev@mail.ru, https://orcid.ord/0000-0002-6833-5005

Светлана Сергеевна Яблочкина, магистрант 1-го курса юридического факультета им. А.А. Хмырова, Кубанский государственный университет, ул. Ставропольская, 149, 350040 г. Краснодар, Российская Федерация, swetlana.jablo4kina@yandex.ru, https://orcid.org/0000-0001-8124-213X 